\section{Atomic surrounding of Co implanted in AIN at high energy}

\section{Agnès Traverse, Anne Delobbe, Didier Zanghi, Mario Rentería, Marc Gailhanou}

\section{Laboratoire pour I'Utilisation du Rayonnement \\ Electromagnétique, Université Paris-Sud, Bât. 209 A, B.P. 34, 91898 Orsay CEDEX, France}

AlN bulk ceramic has been implanted with energetic Co ions. In order to accurately characterise the atomic surrounding of the implanted ions, X-ray absorption measurements were carried out at $80 \mathrm{~K}$ in the fluorescence mode at the Co K edge in the as-implanted and annealed states. Simulation of the EXAFS oscillations allowed us to identify a first stage where Co is inserted in the AIN matrix followed by a second stage where Co precipitates form.

\section{Keywords : ion implantation, AIN, cobalt}

\section{Introduction}

Ion implantation is often regarded as a tool to prepare out-ofthermodynamic equilibrium systems with improved surface properties. Since these properties depend on the phases formed during the slowing down process of the energetic incoming ion, it is important to characterise them from a crystallographic point of view and to look at their stability. We previously showed that $\mathrm{Cu}$ (Borowski et al., 1994) and Ni ions (Traverse, 1997) implanted at room temperature with incident energies less than $100 \mathrm{keV}$ in AlN form metallic clusters after an annealing treatment typically at $800^{\circ} \mathrm{C}$ for one hour under vacuum. From the analysis of the phases formed after implantation of different ions in different matrices, at about 100 $\mathrm{keV}$, we deduced in a recent article that Co must precipitate to form clusters in AIN (Zanghi et al., 2000). The goal of the work presented here is to identify the local environment of Co implanted at high energy $(300 \mathrm{keV})$ in the AlN ceramic in the as-implanted state and after annealing at $800^{\circ} \mathrm{C}$ for 9 hours under vacuum. Because the incident energy is increased as compared to our previous work, the width of the implantation profile is larger. The consequence is that the ions are also located, on the average, at larger distances from each other than in the previous situation. Hence, the interaction with the matrix atoms and between themselves should be modified. Indeed, we found that Co ions are inserted in the AlN matrix in the as-implanted state, the thermal treatment leading to the formation of Co clusters with Co-Co bonds long of $2.50 \AA$ as in bulk Co.

\section{Experimental}

Two pieces of AlN bulk ceramic were simultaneously implanted on the Aramis accelerator (Bernas et al., 1992) with $5 \times 10^{16} \mathrm{Co} / \mathrm{cm}^{2}$ at $300 \mathrm{keV}$ and room temperature. One sample was kept in the asimplanted state whereas the other one was annealed at $800^{\circ} \mathrm{C}$ for 9 hours under vacuum.

$\mathrm{X}$-ray absorption spectroscopy was performed at the Co $\mathrm{K}$ edge on the H10 station of the DCI storage ring in Orsay (Gailhanou et al., 2000). The samples were mounted in a liquid nitrogen cryostat and measured in the fluorescence mode, either with $0.5 \mathrm{eV}$ steps on the $7600-7900 \mathrm{eV}$ energy range (XANES) or with $2 \mathrm{eV}$ steps on the $7600-8600 \mathrm{eV}$ energy range (EXAFS). For comparison, a Co foil was also measured in the transmission mode. The absorption coefficients were treated in the usual way, i.e. subtraction of the preedge, extraction of the oscillations and calculation of the Fourier transform on the 3 to $11 \AA^{-1}$ range (Michalowicz, 1991). Simulation of the filtered peaks was done using phase and amplitude either experimental or calculated depending on the type of neighbour.

\section{Results}

The XANES spectra obtained on the as-implanted and annealed samples are presented in Fig. 1.

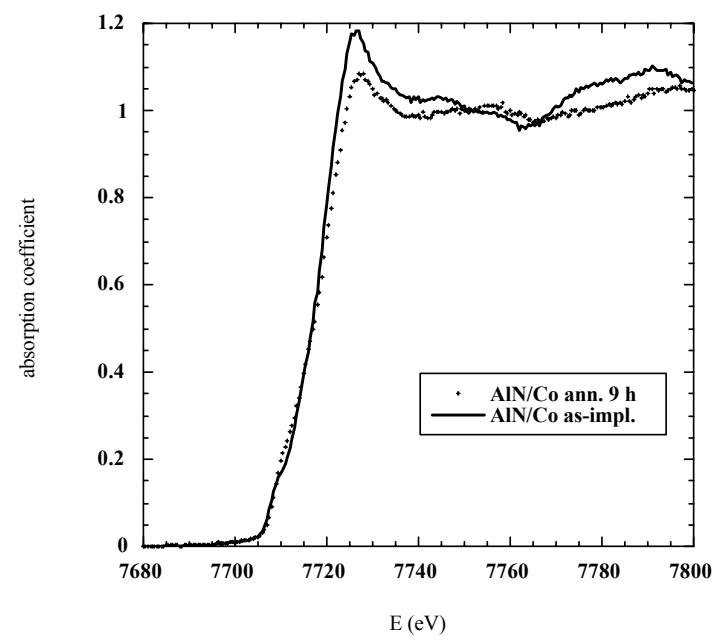

Figure 1

XANES at the Co $\mathrm{K}$ edge on the as-implanted and the annealed AlN implanted with Co at $300 \mathrm{keV}$.

An evolution between the two Co atomic surrounding due to the thermal treatment is already detected by the XANES modification, that is confirmed by the EXAFS oscillations and the Fourier transforms presented in Fig. 2 and Fig. 3.

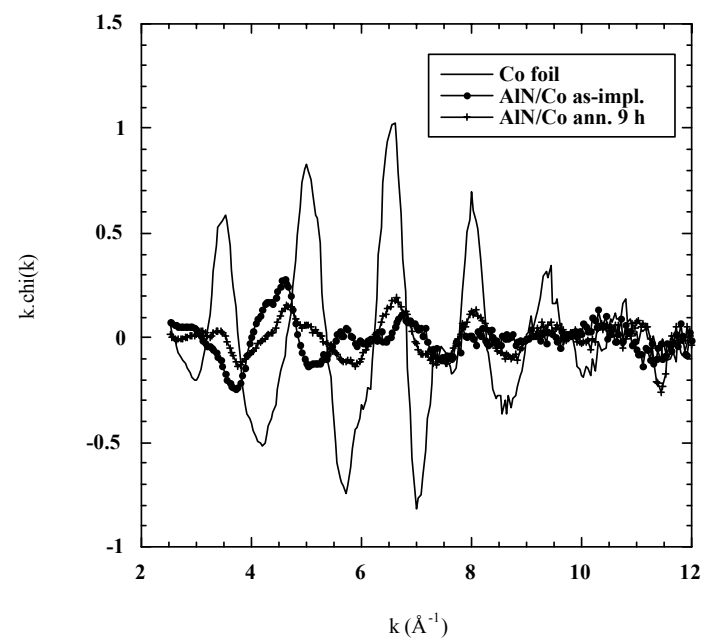

Figure 2

EXAFS oscillations at the Co $\mathrm{K}$ edge on a Co foil and on the as-implanted and the annealed AlN implanted with Co at $300 \mathrm{keV}$.

We note that the oscillations and the Fourier transforms are clearly different from those of a Co foil. A consequence is that, around $\mathrm{Co}$, one must take into account other types of neighbours than Co only. 
Moreover, it is clear from Fig. 3 that no long range crystalline order takes place even after the thermal treatment.

The two first peaks of the Fourier transform for the as-implanted sample and the first peak for the annealed one were filtered (from 1 $\AA$ to $3 \AA$ uncorrected from phase shift) and the obtained oscillations fitted to obtain the type of neighbours, number and distances.

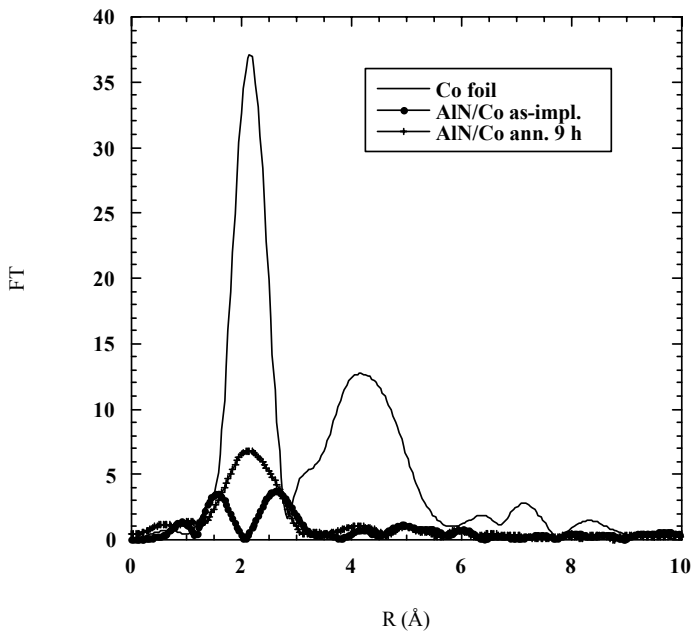

Figure 3

Fourier transforms on a Co foil and on the as-implanted and the annealed AlN implanted with Co at $300 \mathrm{keV}$.

Figs. 4 and 5 display the filters and their fits. Again, a strong evolution, over the whole $\mathrm{k}$ range, is noticeable between the asimplanted and annealed states, indicating an important modification of the Co atomic surrounding.

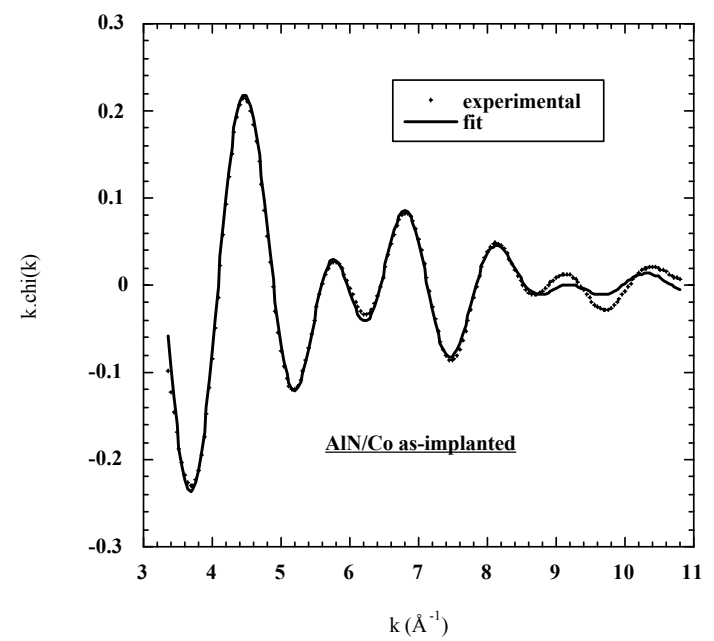

Figure 4

Filter of the two first peaks in the Fourier transform for AlN implanted with $\mathrm{Co}$ at $300 \mathrm{keV}$ and its simulation.

During their slowing down process, Co ions loose their energy that induce a breaking of the Al-N and Al-Al bonds. There is thus a possibility for $\mathrm{Co}$ to bond to the matrix atoms. Since $\mathrm{Al}_{\mathrm{x}} \mathrm{Co}_{1-\mathrm{x}}$ compounds have negative heat of formation (Miedema, 1988), a first attempt was to check the possibility of such compound formation. However, it was not possible to obtain fits of good quality, assuming the existence of a first $\mathrm{Al}$ shell located at $2.47 \AA$ as in $\mathrm{Al}_{5} \mathrm{Co}_{2}$ or at $2.50 \AA$ as in $\mathrm{AlCo}$, and a second Co shell located at $2.94 \AA$ as in $\mathrm{Al}_{5} \mathrm{Co}_{2}$ or at $2.85 \AA$ as in $\mathrm{AlCo}$. By allowing the distances to vary, the fit gives an Al-Co shell located at about $2.23 \AA$, too short to be reliable.

Hence, we took another assumption, i.e. Co in substitution of $\mathrm{Al}$ in the AlN wurtzite structure. Due to the positive ionic character of this site, this is the only possible one for an incident Co ion. In this wurtzite structure, around an $\mathrm{Al}$ atom, there is a first shell of $4 \mathrm{~N}$ located at $1.89 \AA$, then $12 \mathrm{Al}$ at $3.09 \AA$. The occupancy of the $\mathrm{Al}$ site by Co implies that $\mathrm{Co}$ is surrounded by a shell made of $\mathrm{N}$ atoms, although the Co-N bond is not thermodynamically favoured (Smithells, 1983).

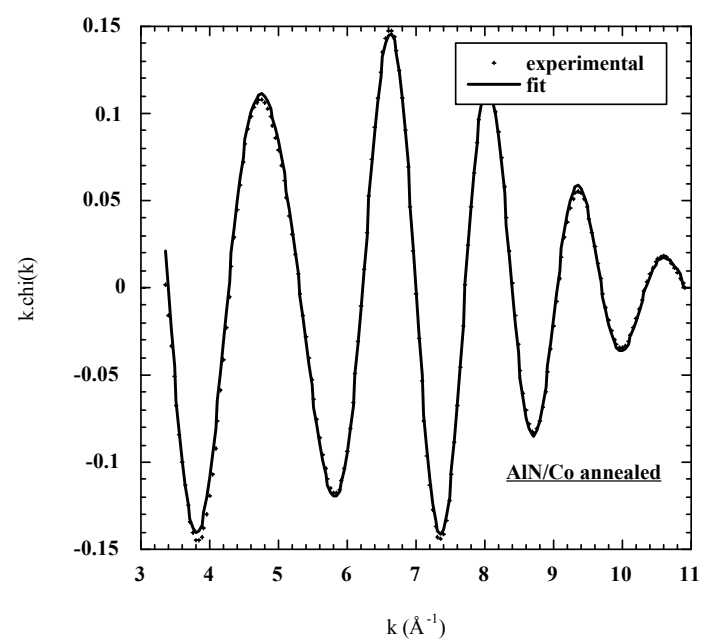

Figure 5

Filter of the first peak in the Fourier transform for AlN implanted with Co at $300 \mathrm{keV}$ then annealed and its simulation.

For the $\mathrm{N}$ shell, we took the phase and amplitude calculated by McKale (McKale, 1988). For the Al shell, as $\mathrm{Si}$ is the $\mathrm{Al}$ neighbour in the periodic table, we took the phase and amplitude extracted from the first filtered peak of a $\mathrm{CoSi}_{2}$ compound measured at the Co $\mathrm{K}$ edge. For $\mathrm{Co}-\mathrm{Co}$, we took the phase and amplitude extracted from the Co foil. Results of the fitting procedure are presented in Table 1.

Table 1

Results of simulation as compared to $\mathrm{Al}$ environment in AlN

\begin{tabular}{cccc}
\hline $\begin{array}{c}\text { Type of } \\
\text { neighbour }\end{array}$ & $\begin{array}{c}\text { AlN/Co } \\
\text { as-implanted }\end{array}$ & $\begin{array}{c}\text { AlN/Co } \\
\text { annealed }\end{array}$ & $\begin{array}{c}\text { Al in } \\
\text { AlN }\end{array}$ \\
\hline $\mathrm{N}$ & 4 at $2.03 \AA$ & 2 at $2.03 \AA$ & 4 at $1.89 \AA$ \\
& $\sigma=0.098 \AA$ & $\sigma=0.090 \AA$ & \\
Al & 8 at $3.03 \AA$ & 6 at $3.02 \AA$ & 12 at $3.09 \AA$ \\
& $\sigma=0.088 \AA$ & $\sigma=0.080 \AA$ & \\
Co & 4 at $3.28 \AA$ & 3 at $2.50 \AA$ & \\
& $\sigma=0.154 \AA$ & $\sigma=0.045 \AA$ & \\
& &
\end{tabular}

In the AlN/Co as-implanted sample, around $\mathrm{Co}$, the first $\mathrm{N}$ shell with 4 atoms is identified. Then the second shell of $8 \mathrm{Al}$ atoms is found located at $3.03 \AA$, followed by $4 \mathrm{Co}$ at $3.28 \AA$. This result supports the assumption of $\mathrm{Co}$ in substitution of $\mathrm{Al}$ in the AlN matrix.

After annealing, the $\mathrm{Co}-\mathrm{N}$ and $\mathrm{Co}-\mathrm{Al}$ distances are kept, but the number of $\mathrm{N}$ and $\mathrm{Al}$ neighbours has decreased to half the value in AlN. The noticeable evolution is that the Co shell has disappeared and a new one is created where the Co atoms are now located at a 
distance of $2.50 \AA$, i.e. the distance in bulk Co. This large distance reduction, out of uncertainty, is a strong indication of $\mathrm{Co}$ precipitation to form clusters.

The Debye-Waller factor is systematically slightly decreased by the thermal treatment as expected. It is rather small in the case of the Co clusters $(0.045 \AA)$ in agreement with previous results for $\mathrm{Ni}$ in $\mathrm{AlN}$ (Zanghi et al., 2000).

\section{Discussion}

Due to the large number of parameters used in the fitting procedure, we must consider that the uncertainty on $N$ is not better than \pm 1 and $\pm 0.02 \AA$ on $\mathrm{R}$. Thus, in the following, we will discuss the motion of the Co atoms from the $\mathrm{Al}$ site in AlN to Co cluster, rather than the absolute parameters values.

Although unexpected in view of the positive heat of formation of the $\mathrm{Co}_{3} \mathrm{~N}$ nitride (Smithells, 1983), the assumption of Co substitution to $\mathrm{Al}$ in the AlN matrix appears reasonable as indicated by the surrounding that is deduced from the fit. There are $4 \mathrm{~N}$ at a larger distance than in $\mathrm{AlN}$, this can be due to the Co ionic radius $(0.65 \AA$ for $\left.\mathrm{Co}^{3+}\right)$ larger than the one of $\mathrm{Al}\left(0.57 \AA\right.$ for $\left.\mathrm{Al}^{3+}\right)$ (Smithells, 1983). An Al shell is present at a distance a little bit shorter than in AlN with only 8 atoms. However a Co shell is detected, the total amount of $\mathrm{Al}+\mathrm{Co}$ atoms being 12, i.e. the expected number of $\mathrm{Al}$ atoms in AlN. One can thus consider that part of the $\mathrm{Al}$ shell is filled with Co atoms.

This situation appears to be strongly unstable under thermal treatment in the conditions used here. Part of the Co atoms went out of the $\mathrm{Al}$ site, as indicated by the fact that only $2 \mathrm{~N}$, half of the initial value, and $6 \mathrm{Al}$ are then measured and also that the Co shell located at $3.28 \AA$ disappeared. The $\mathrm{Co}$ ions that have left the $\mathrm{Al}$ site precipitate to form Co clusters as indicated by the Co-Co shell located at $2.50 \AA$.

This result is in full agreement with those previously published on $\mathrm{Cu}$ (Borowski et al., 1994) and Ni ions (Traverse, 1997) implanted in AlN. The interpretation, presented in Zanghi et al. (2000) is that the final system can be predicted by writing the reaction equation, i.e.

$$
\begin{array}{ll}
\mathrm{AlN}+\mathrm{Co} \rightarrow \mathrm{AlCo}+1 / 2 \mathrm{~N}_{2} & \Delta \mathrm{H}_{\mathrm{R}}=+208.2 \mathrm{~kJ} / \mathrm{mol} \\
5 \mathrm{AlN}+2 \mathrm{Co} \rightarrow \mathrm{Al}_{5} \mathrm{Co}_{2}+5 / 2 \mathrm{~N}_{2} & \Delta \mathrm{H}_{\mathrm{R}}=+1299 \mathrm{~kJ} / \mathrm{mol}
\end{array}
$$

The positive heat of reaction indicates that the $\mathrm{AlCo}$ and $\mathrm{Al}_{5} \mathrm{Co}_{2}$ compounds cannot form in agreement with the impossibility to get good fits with these assumptions. The possibility of $\mathrm{Co}_{3} \mathrm{~N}$ formation is not considered as its heat of formation is positive (Smithells, 1983). Thus the only remaining possibility for Co is to form clusters. The Al substitution by a Co ion that is observed here in the asimplanted state is not in contradiction with what is written above. It represents the first stage of a process where the stopping site for Co after the implantation process is the $\mathrm{Al}$ site. This site being unstable as explained by the positive heat of formation of $\mathrm{Co}_{3} \mathrm{~N}$ (Smithells, 1983), thermal energy induces a migration out of this site and a Co precipitation. The annealing conditions used here are not sufficient to induce a total Co precipitation. The temperature should be probably higher than $800^{\circ} \mathrm{C}$.
Note that a substitution of Al by Ti was already observed just after Ti implantation in AIN (Borowski et al., 1994). However, since the Ti-N bond is thermodynamically favoured, this substitution is not unexpected. Indeed, the TiN compound is finally formed at the expense of AlN after annealing.

The fact that part of the Co ions have precipitated and that part of them are still in the $\mathrm{Al}$ sites is not contradictory with the $\mathrm{Ni}$ and $\mathrm{Cu}$ precipitation mentioned above. These ions were implanted at lower energy, thus are located closer from each other than in the case described here. Taking into account the measured width of the implanted profiles and assuming that the ions are distributed over this width on a cubic lattice, a crude evaluation of the average distance between Co ions after implantation is $4.2 \AA$ for $80 \mathrm{keV}$ incident energy and $6.3 \AA$ for $300 \mathrm{keV}$ incident energy. These distances are clearly larger than those measured by XAS, i.e. $2.5 \AA$ for $80 \mathrm{keV}$ where clusters have already formed and $3.28 \AA$ for 300 $\mathrm{keV}$ (Table 1). This can be interpreted by saying that the implanted ions have already started to interact during the implantation process. As the interaction length is probably finite, supplementary energy is required in the latter case to induce cluster formation than in the former one.

\section{Conclusion}

Co ions implanted at $300 \mathrm{keV}$ and room temperature were found to occupy the Al site in the AlN matrix. In this site, Co is surrounded by a $\mathrm{N}$ shell, in contradiction with the fact that the $\mathrm{Co}-\mathrm{N}$ bond is not thermodynamically favoured as indicated by the positive heat of formation of $\mathrm{Co}_{3} \mathrm{~N}$ (Smithells, 1983). However this site is unstable and the thermal treatment leads to Co mobility out of this site to the benefit of Co cluster formation. Indeed this latter system is the one predicted when one writes the reaction equation between AIN and Co. The as-implanted state appears thus as an out of equilibrium system, unstable under annealing.

\section{References}

Bernas, H. ,Chaumont, J., Cottereau, E., Meunier, R., Traverse, A., Clerc, C., Kaitasov, O., Lalu, F., Le Du D., Moroy G. and Salomé, M. (1992) Nucl Instr. and Meth. B62, 416

Borowski, M., Traverse A. and Mimault, J. (1994) Acta Physica Polonica A 86,713

Gailhanou, M., Dubuisson, J.M., Ribbens, M., Roussier, L., Bétaille, D., Créoff, C., Lemonnier, M., Denoyer, J., Jucha. A., Lena, A., Idir, M., Bessiere, M., Thiaudière, D., Hennet, L., Landron, C., Coutures, J.P. (2000) submitted to Nucl Instr. and Meth.A

McKale, A.G (1988) J. Am. Chem. Soc. 110, 3763

Michalowicz, A. (1991) Logiciels pour la chimie, Ed. Soc. Française de Chimie, Paris, 102

Miedema, (1988) Cohesion in Metals, Transition Metal Alloys, F.R. de Boer, R. Boom, W.C.M. Mattens, A.R. Miedema, A.K. Niessen, North Holland, 1988

Smithells Metals Reference Book, 6th ed., edited by E.A. Brandes (Butterworth, London, 1983)

Traverse, A. (1997) Hyperfine Interactions 110, 159

Zanghi, D., Traverse, A., Gautrot, S., and Kaïtasov, O. (2000) submitted to Jou. of Mat. Res.

Zanghi, D., Traverse, A., Dallas, J.-P., and Snoeck, E. (2000) to be published in Eur. Jou. of Phys. D 